\title{
SEXUAL AND REPRODUCTIVE HEALTH OF LOW INCOME ADOLESCENCE GIRLS IN NEPAL: CAN EDUCATION BE A CATALYST?
}

\author{
Prabha Kumari Hamal, Ph.D.*
}

\begin{abstract}
Using data from five districts of Mid-Western and Far-Western Development Region, this paper reaches to conclusion that education has significant and influential roles in determining the sexual and reproductive health of adolescence girls, particularly of those who are from low income families. A rough ' $U$ ' shaped relationship between education and reporting of health problems and gender-based violence was observed.
\end{abstract}

Key words: sexual and reproductive health, low income adolescence, girls, Nepal, education, catalyst

\section{INTRODUCTION}

Within the unbinding arguments, sexual and reproductive health encompasses development and maintenance of meaningful interpersonal relationships; appreciating one's own body; interacting with both - male and female- in respectful and appropriate ways; and expressing affection, love and intimacy in ways consistent with one's own values (Tolman, Striepe and Harmon,2003). It is more concisely explained as the experience of ongoing process of physical, psychological and socio-cultural wellbeing related to sexuality (PAHO; WHO; 2000). Adolescence comprises both biological and social transition in a life cycle. This period has several important marks in the life of girls in particular. The menarche alone brings several changes in psychological and behavioural aspects of a girl, particularly in societies with conventional lifestyles. The complexities continue in the later stages in negotiation dynamics on marriage, fertility, use of contraception and other practices of safer sex, particularly due to gender ideals (Varga 2003). Sexual and reproductive health can be a function of a range of factors including psychological, physical, societal, cultural, educational, economic and spiritual factors (Tolman, Striepe and Harmon 2003).

Limiting the broad theoretical spectrum of determinants of sexual and reproductive health, this paper is little selective in its structure focusing on the educational dimension. Since education is an important determinant of individual behaviour and perception, its contributions are both intrinsic and instrumental. Evidences support the existence of

* Ms. Hamal Associate Professor at the Central Department of Population Studies, Tribhuvan University 
multiplier effect of education offering changes in adolescence reproductive behaviour including application of safe health practices. With an improvement in educational status, girls tend to exercise liberal social and cultural traits.

Access to resources determines the health status. A limited or shrunken access to resource implies shrinking opportunities and reduced scope including premature exit from school, reduced earnings prospects, reduced chances of community participation and acquisition of social capital and fallen health opportunities, thereby increasing risk in living poverty (Greene and Merrick, 2005). Gendered practices and norms even increase risk for adolescence girls who suffer family hardship at the first. Evidences show girls from economically marginal households either do not enter school or dropout early and begin family life early. Early initiation of reproductive activities promotes a vicious cycle of poverty by increasing the health care cost and limiting the capability enhancement opportunities.

\section{SCOPE, AIM AND DATA}

Using the data from five districts of Nepal - Kailali, Dadeldhura, Bajhang, Jajarkot and Salyan- from field survey in January 2009, this article is entitled to discover the reproductive health status of women aged 10 years and above at large and of adolescence girls in particular. A total of 708 women aged 10 years and above were interviewed from five districts using cluster sampling from low income households. However, this article is built on sample of 199 females in the age group 10-19 years which is 29 percent of the total sampled women. Using education as one of the major determinants of individual's health, this article elucidates sexual and reproductive health status of adolescents. Another contribution of the article would be to know the sexual and reproductive health status of women in conflict affected areas in postconflict situation. This may help to design some interventions to protect the sexual and reproductive rights of women in conflict sensitive areas in the future.

\section{Demography of Adolescence Girls}

The proportion of young people, at present, is the largest in the world demographic history (UNFPA 2005). Nepal is predominantly young country where the median age of population is 20 years - male 19 and female 20 years (Pantha and Sharma 2003).

Table 1: Marital status by level of education

\begin{tabular}{|c|c|c|c|c|}
\hline Level of education & & Never married & Currently Married & Total \\
\hline $\begin{array}{l}\text { No education } \\
\text { Primary level } \\
\text { Some Secondary level } \\
\text { SLC and above }\end{array}$ & & $\begin{array}{l}47.1 \\
90.4 \\
84.6 \\
69.6\end{array}$ & $\begin{array}{c}52.9 \\
9.6 \\
15.4 \\
30.4\end{array}$ & $\begin{array}{l}100.0 \\
100.0 \\
100.0 \\
100.0\end{array}$ \\
\hline & $\%$ & 82.4 & 17.6 & $100.00^{* * *}$ \\
\hline & $\mathrm{N}$ & 164 & 35 & 199 \\
\hline
\end{tabular}

Source: Field Survey 2009.

${ }^{* * *} \chi^{2}$ value significant at $\mathrm{p}<0.01$ level. 
The age structure favours adolescence girls (10-19 years) with an increase of 2.23 percent point between 1991 and 2001, 21.08 and 23.21 percent respectively. The adolescence girls make up more than one fifth in total female population (Central Bureau of Statistics 2002). Within the adolescence girls, more than 50 percent are in early adolescence, 10-14 years, which is consistent to the study population. The median age at marriage for women aged 20-24 is 17.9 years, an improvement of 1.4 years over the women of aged $45-49$. While the median age at first sexual intercourse is not significantly different than that of age at marriage. Both indicators vary along with the improvement in the educational attainment (Ministry of Population and Health (MoHP) [Nepal]; New ERA; Macro International Inc., 2007).

In the sample population, 17.6 percent adolescent girls were ever married and the percentage is highest for illiterate adolescents (52.9\%) and least for girls in the primary level of education (9.6\%), implying that once a girl joins school her probability of marrying at early age significantly decreases (Table 1). Of those ever married, more than two thirds have had at least one live birth while 3 in 10 have had at least 2 pregnancies during the late adolescence. Slightly more than one quarter ever married adolescence girls were pregnant at the time of survey.

\section{FAMILY PLANNING AND MATERNAL HEALTH}

Slightly more than 4 in 10 adolescence girls were using contraception and those not having education were less likely to use. Desire of a child was a major reason for those not using contraception. Encouragingly, all pregnant adolescence girls were receiving antenatal care visits and less than 1 in 10 reported to have unwanted pregnancy.

\section{Reproductive Health Problem}

For the analysis, from a list of reported 30 sexual and reproductive health problems five major categories were constructed - pregnancy and delivery related, anemia and hemorrhage related, chronic complication, abortion related and STDs and the rest into 'Others'. Nearly half of the adolescence girls have had at least a type of sexual and reproductive health problem in the last five years, which indicates an emerging but serious health concern among rural adolescence girls. Although, no clear relationship between educational attainment and sexual and reproductive health problems of adolescents, a small proportion of 'No health problem' with no education leaves a room for making a conclusion of some possible relationship between education and health problem. A roughly ' $U$ ' shaped relationship between education level and reported reproductive health problem is observed (Figure 1). This has two possible implications. First, adolescence girls with no education are more likely have reproductive health problems.

This has an obvious reason including practice of unsafe sexual behaviours and lack of awareness about preventive measures. Second, with the increase in education, the health seeking behaviour increases and adolescence girls are more likely to report their health problems. For policy implication, the prevalence of sexual and reproductive health problems among uneducated adolescence girls should attract for intervention. 
Eight percent of adolescence girls reported to have experienced pregnancy and delivery related problems, followed by anemia and hemorrhage $(7 \%)$ and STDs (7\%) whereas four percent had abortion related problems and two percent had chronic complications like uterus prolapsed and obstetric fistula.

\section{Treatment Seeking Behaviour}

Only half of the adolescence girls having reproductive health problem reported to have visited health facilities for treatment. The indicator is favourable to girls with no education $(68 \%)$ and the reasons are unknown. But one possible reason may be that they had also reported higher prevalence of health problems.

Proportion of adolescence girls seeking treatment is the lowest among the primary level education $(42 \%)$ and then steadily increases along with the improvement in education. This leads to a conclusion that low level of education is not enough to motivate adolescence girls for health promotion.

Reasons for not seeking treatment were economic and quality of service available in the health institutions. An overwhelmingly large proportion of adolescence girls who visited health institutions were encouraged by family members, friends and relatives; followed by Female Community Health Volunteer (FCHV). Adolescence girls with low level education were more likely to depend on the suggestions of family member, friends and relatives. Nearly half of the adolescence girls were still facing the problems they had earlier and the proportion is higher for adolescence girls with lower education.

\section{Gender-Based Violence}

Gender based-violence is considered as both cause and consequence of poor reproductive health outcome. It has long lasting adverse consequences for women's reproductive health (UNFPA; UNIFEM; 2005). Unwanted pregnancies, maternal death, miscarriage, injury and STDs are a few of them. Studies have shown some obvious relationship between education and gender-based violence. However, such relationship appears elusive in many developing societies.

Figure 3 shows an elusive relationship between education and gender based-violence. A total of nine percent adolescence girls reported to have experience gender based violence. Interestingly, educated adolescence girls are more likely to report the cases of violence against them. The highest proportion (21.7\%) of girls with SLC and above level of education reporting gender based violence against them implies that education has brought awareness to defy the injustice, which the low education girls may not do. But figure does not approve that women with low education are less likely to experience gender-based violence. In fact, they report less as in many cases they internalize violence against them. Taking help in the cases of violence is extremely low as more than half of those experiencing violence did not seek help. In which more were having low level of education. 


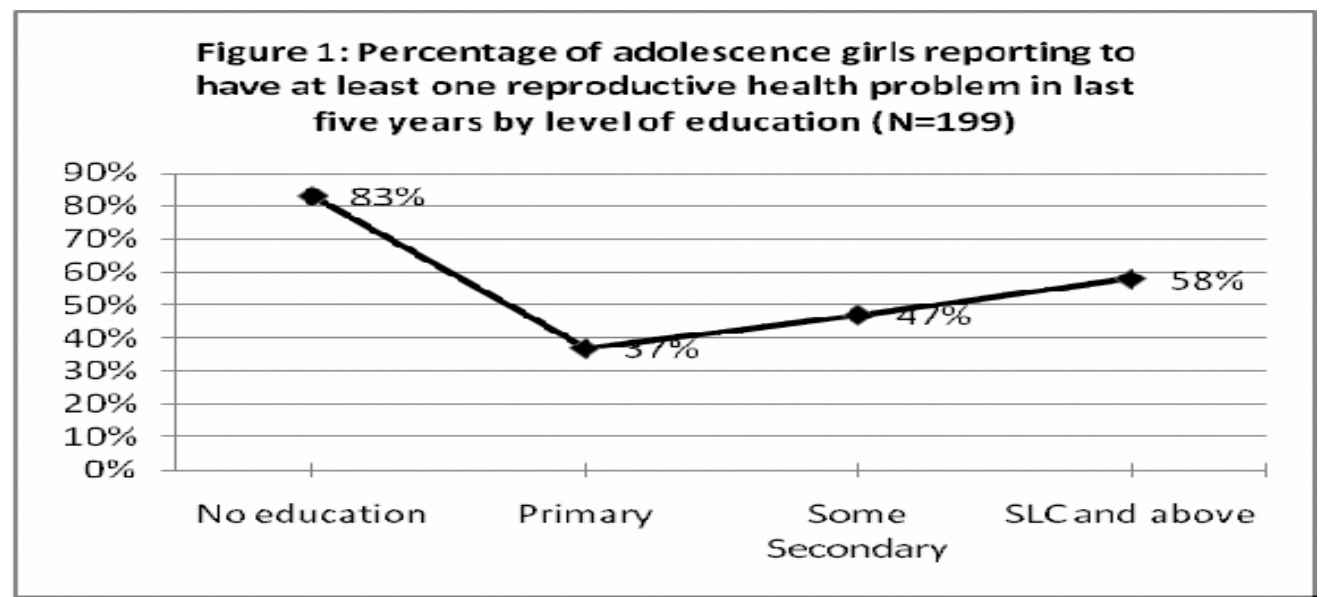

\section{DISCUSSION AND CONCLUSION}

Education benefits girls from different dimensions. It can be an important wealth of those who lack other resources. Improvement in sexual and reproductive health is one important dimension in which educational attainment can contribute. Sexual and reproductive health is more contextualized (Billy, Brewster and Grady 1994), in which personal characteristics of adolescence girls may have visible influence. The behaviours like whether and when to marry, whether and when to have a child, how many children to have, whether and when to apply contraceptives, whether to seek treatment in case of illness and whether to resist or report the violence are influenced by the level of understanding and exposure a girl has. Adolescence girls with good education background feel comfortable to deal with the issues discussed above.

This paper as a part of large project approves the positive contribution of education on sexual and reproductive status of adolescence girls. This paper also qualifies the gendered sexual and reproductive health of adolescent girls (Tolman, Striepe and

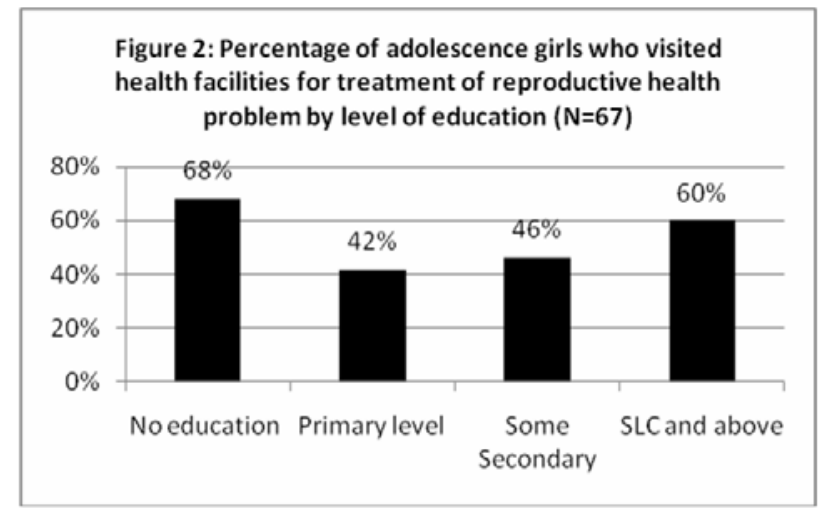


Harmon 2003). In countries like Nepal, where health service delivery is notoriously difficult (Campbell, et al. 2003), adolescence sexual and reproductive health gets little attention in the policy discourse.

Investments in education of girls have tangible social and economic benefits reflected in delayed marriage, reduced fertility, improved child survival and reduction in health care cost. School education is the only catalyst that can reduce the probability of marriage and birth at early age offering incalculable contribution in promotion of sexual and reproductive health. Education has both intrinsic and instrumental values. However, benefits may vary considerably by setting (Murphy and Carr 2007), including the economic status.

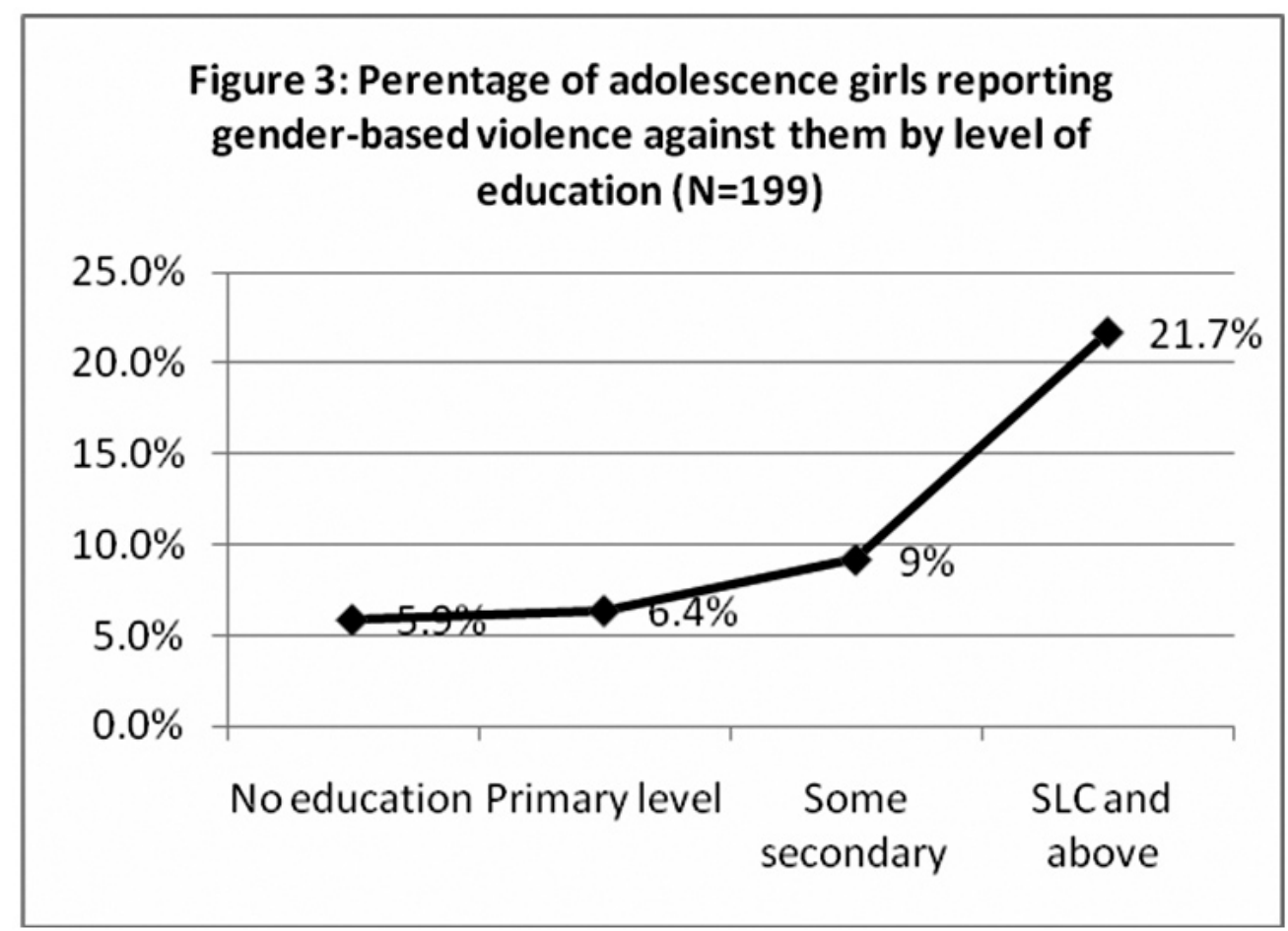

Poverty manifests the health consequences resulting deprivation of education and other opportunities. In Nepal where female literacy is considerably low, increasing investment in education of girls is an important measure to promote the sexual and reproductive health and contribute to reduce burden of poverty arising from health care cost. Targeting girls from low income family in their education has greater strategic importance than anything else. Education opens window of opportunities. 


\section{Acknowledgements}

The author is thankful to United Nations Population Fund, Nepal for providing financial support to carry out the research project.

\section{Bibliographies}

Billy, John, O.G, Karin L. Brewster, and William R. Grady.(1994). Contextual Effects on the Sexual Behavior of Adolescent Women. Journal of Marriage and Family, 56( 2): 387-404.

Campbell, Bruce B, Ietje H Reerink, Francoise Jeeniskens, and Laxmi R Pathak.(2003). A Framework for Developing Reporductive Health Policies and Programmes in Nepal. Reproductive Health Matters : 171-182.

Central Bureau of Statistics (2002). Population Census National Report Vol I. Kathmandu: Central Bureau of Statistics.

Ministry of Population and Health (MoHP) [Nepal]; New ERA; Macro International Inc. (2007).. Nepal Demographic and Health Survey 2006. Kathmandu: Ministry of Health and Population, New ERA, and Macro International Inc.

Murphy, Elaine, and Dara Carr(2007). Adolescent Gilrs' Education and Delayed Childbearing . New York, September 2007.

PAHO and WHO.(2000). Promotion of Sexual Health Recommendations for Action. Antigua: Pan American Health Organization and World Health Organization.

Pantha, R, and Bharat Raj Sharma(2003). Population Size, Growth and Distribution. In Population Monograph of Nepal Vol. I, 37-86. Kathmandu: Central Bureau of Statistics,

Tolman, Deborah L., Meg I. Striepe, and Tricia Harmon (2003). Gender Matters: Constructing a Model of Adolescent Sexual Health. The Journal of Sex Research, 40( 1), 4-12.

UNFPA.(2005). State of World Population 2005. New York: UNFPA.

UNFPA; UNIFEM.(2005). Combating Gender Based-Violence: A Key to Achieving the MDGs. New York: United Nations.

Varga, Christine A.(2003). How Gender Roles Influence Sexual and Reproductive Health Among South African Adolescents. Studies in Family Planning, 34(3), 160-172. 